\title{
Vacuum-assisted cesarean section
}

This article was published in the following Dove Press journal:

International Journal of Women's Health

7 March 2017

Number of times this article has been viewed

\section{Ross W McQuivey' Jon E Block ${ }^{2}$}

'Clinical Innovations, Salt Lake City, UT, ${ }^{2}$ Independent consultant, San Francisco, CA, USA
Correspondence: Jon E Block

2210 Jackson Street, Suite 40I,

San Francisco, CA 94II5, USA

Tel +I 4157757947

Fax + I 4I59280765

Email jb@drjonblock.com
Abstract: There has been a dramatic rise in the frequency of cesarean sections, surpassing $30 \%$ of all deliveries in the US. This upsurge, coupled with a decreasing willingness to allow vaginal birth after cesarean section, has resulted in an expansion of the use of vacuum assistance to safely extract the fetal head. By avoiding the use of a delivering hand or forceps blade, the volume being delivered through the uterine incision can be decreased when the vacuum is used properly. Reducing uterine extensions with their associated complications (eg, excessive blood loss) in difficult cases is also a theoretical advantage of vacuum delivery. Maternal discomfort related to excessive fundal pressure may also be lessened. To minimize the risk of neonatal morbidity, proper cup placement over the "flexion point" remains essential to maintain vacuum integrity and reduce the chance of inadvertent detachment and uterine extensions. Based on the published literature and pragmatic clinical experience, utilization of the vacuum device is a safe and effective technique to assist delivery during cesarean section.

Keywords: cesarean section, vacuum, forceps, birth, delivery

\section{Introduction}

The rate of cesarean delivery has increased dramatically worldwide over the past several decades and now exceeds $55 \%$ of all deliveries in many countries. ${ }^{1}$ In the US, cesarean section frequency has surpassed $30 \%$ for nearly a decade, ${ }^{2,3}$ with a wide distribution that ranges from $7.1 \%$ to $69.9 \%$ across hospitals. ${ }^{4}$ Despite public health efforts to optimize and curtail cesarean section utilization, ${ }^{5}$ delivery rates by this method continue to rise unabated. ${ }^{6}$ Consequently, physicians will increasingly encounter a wider variety of clinical presentations that necessitate availability of the full range of delivery options to manage different medical scenarios and maximize outcomes.

Once established as a safe and effective method of operative vaginal delivery, ${ }^{7,8}$ vacuum-assisted procedures have more recently shown clinical utility and have become widely adopted for cesarean section. ${ }^{9}$ In an elective cesarean section, the lower uterine segment is commonly not elongated or effaced by labor, making it difficult to create an adequate incision to enable an uncomplicated delivery. In addition, at the time of an elective repeat cesarean section, the fetal head is normally not deeply engaged in the pelvis. Procedures to facilitate delivery in this situation include fundal pressure, forceps, internal podalic version, or addition of a lateral vertical incision ("J" incision), all of which can be traumatic for both mother and fetus. ${ }^{10}$ The advantages of using a vacuum device in this situation to assist delivery of the fetal head are listed in Table 1.

Herein, we review the published findings on maternal and neonatal outcomes and provide perspective on the clinical benefits of vacuum-assisted cesarean section.

\section{Historical perspective}

To identify published literature relevant to vacuum-assisted cesarean section, a computer-based electronic search of the PubMed and Web of Science databases up to 
Table I Potential advantages of vacuum-assisted cesarean section

I. The ability to decrease the volume of the fetal head by avoiding the use of a delivering hand or forceps blade

2. The ability to avoid traumatic or deliberate extension of the uterine incision, along with decrease in associated blood loss

3. The ability to decrease the amount of fundal pressure necessary for delivery, thus reducing maternal discomfort

and including May 2016 was conducted. The search strategy included common words and terms related to vacuumassisted deliveries, especially during cesarean section. Also reviewed were unpublished studies to determine whether there were data sets that may be informative. Finally, bibliographies of all relevant papers were hand searched for applicable articles.

Having already achieved widespread clinical acceptance as a mainstay procedure in operative vaginal deliveries, vacuum-assisted cesarean section was first described by Solomons ${ }^{11}$ in his seminal report of 20 consecutive cases delivered with the $5 \mathrm{~cm}$ Malmström cup. All 20 infants were successfully delivered by this method, and the occurrence of caput succedaneum (chignon), typically produced by the vacuum cup, was much less apparent in these newborns. It was hypothesized that this was due to the less time and traction force required to deliver via an abdominal incision compared to the effort required to deliver the fetal head across the pelvic floor as with operative vaginal delivery.

Also using the original Malmström cup, Bercovici ${ }^{12}$ successfully delivered 20 of 22 (91\%) term infants via cesarean section without uterine extensions. A small chignon was noted on all infants, which resolved within 2 days. In one case, delivery failure was ascribed to use of a larger $(6 \mathrm{~cm})$ cup and, in the other case, to a deeply engaged head that was manually delivered. It was concluded that the vacuum was most appropriately indicated for cases where the fetal head is not deeply engaged in the pelvis and does not require manual elevation out of the pelvis prior to the application of the cup.

Pelosi and Apuzzio ${ }^{13}$ published the initial report of the use of a soft vacuum cup (silastic) for cesarean section. Thirtyfive infants were successfully delivered with this method, including 15 primary nonelective cesarean sections without evidence of fetal distress and 20 elective repeat procedures. While there were no uterine extensions or surgical complications in their series, the uniformly encouraging results could not be duplicated by others and, in fact, the popularity of the esthetically pleasing soft vacuum cups has declined substantially given the high detachment and overall failure rates. ${ }^{14}$
In a prospective trial of 18 term, elective cesarean sections, Arad et a $1^{15}$ compared neonatal outcomes between eight patients delivered via vacuum and 10 patients via manual extraction. There were no notable or statistically significant differences between groups for birth weight, Apgar scores, or acid/base status measured from umbilical cord blood gases. The time required from uterine incision to complete delivery was approximately twofold higher in the vacuum group (79.4 vs 40.9 seconds, $P<0.01$ ), but the difference was not clinically significant. Additionally, Arad et a ${ }^{15}$ retrospectively evaluated neonatal outcomes in 78 term, elective cesarean sections performed at their facility over a 4-year period. Again, there was no difference in Apgar scores between 34 infants delivered with vacuum assistance and 44 randomly selected infants delivered manually. These results were corroborated by Boehm, ${ }^{16}$ who reported successful delivery of 50 cases using vacuum-assisted cesarean section, with no neonatal morbidity.

In a randomized controlled trial, Bofill et $\mathrm{al}^{17}$ compared outcomes among 15 patients delivered with vacuum, 14 manually, and 15 by forceps. In the vacuum group, 13 of 15 (87\%) were delivered successfully and the remaining two were delivered manually. One failure was due to a pump malfunction and the other was inadvertently manually delivered when the fetal head was being manipulated prior to cup application. In the manual delivery group, 11 of $14(79 \%)$ were delivered successfully, while three required vacuum assistance to facilitate delivery. Delivery with the aid of forceps was successful in 11 of 15 (73\%) cases; however, three had to be delivered manually and one with vacuum. There were no differences noted across groups for the Apgar scores, cord arterial $\mathrm{pH}$, birth weights of the neonates, extensions of the uterine incision, or the pre- to postdelivery hemoglobin values. The time required to effect delivery tended to be longer in the forceps group ( $P=0.06)$. Importantly, patients reported less pain during delivery in the vacuum group $(P=0.02)$ probably due to the reduced fundal pressure necessary to effect delivery.

Dimitrov et $\mathrm{al}^{18}$ conducted a prospective study comparing vacuum-assisted delivery ( $\mathrm{n}=19)$ with standard manual extraction $(n=25)$ in patients having an elective cesarean section. There were no differences in Apgar scores between groups. However, the duration of scalp traction was significantly shorter than the time necessary for manual extraction ( $30 \pm 4$ vs $53 \pm 21$ seconds, $P<0.01$ ). The authors noted that vacuum delivery was accomplished in all cases without the need for additional fundal pressure.

Most recently, Sritippayawan and Chantrapitak ${ }^{19}$ reported the results of a large randomized controlled 
trial of vacuum-assisted delivery $(n=90)$ compared to manual extraction $(n=90)$ during elective cesarean section. Using a soft cup to assist in the delivery of the unengaged fetal head, the delivery duration was significantly shorter in the vacuum group compared to the manual delivery group (65.3 \pm 31.2 vs $86.3 \pm 53.9$ seconds, $P<0.01$ ). Mean blood loss was slightly higher in the vacuum group $(576.7 \pm 182.9 \mathrm{~mL}$ vs $504.4 \pm 204.9 \mathrm{~mL}, P=0.31$ ), and there was no difference in Apgar scores and no evidence of chignon. The authors concluded that extraction of the fetal head by cesarean section with the vacuum device was safe, rapid, and nontraumatic and did not require the need for prolonged fundal compression.

\section{Current state of the art}

The original metallic Malmström cup vacuum device served as the foundational design for the current-generation rigid cup devices appropriate for use during cesarean section. ${ }^{8}$ One such device is the Kiwi ${ }^{\circledR}$ OmniCup $^{\circledR}$ (Clinical Innovations, Salt Lake City, UT, USA) which uses a $5 \mathrm{~cm}$ rigid plastic cup (Figure 1). This complete vacuum-assisted fetal delivery device is designed for use in all fetal head positions - occiput anterior, occiput posterior, and occiput transverse - and cesarean section procedures. Its flexible stem and low-profile cup enable placement over the flexion point, $3 \mathrm{~cm}$ forward of the posterior fontanelle along the sagittal suture, so that the smallest diameters of the fetal head are presented to the birth canal or the uterine incision depending on the procedure it is being used for.

The Kiwi ${ }^{\circledR}$ OmniCup ${ }^{\circledR}$ was evaluated in a prospective trial comparing the safety and effectiveness of delivery of the fetal head during cesarean section compared to the traditional method of manual extraction (McQuivey, unpublished data). Twenty-five patients were allocated to each treatment arm. Estimated blood loss was lower in the

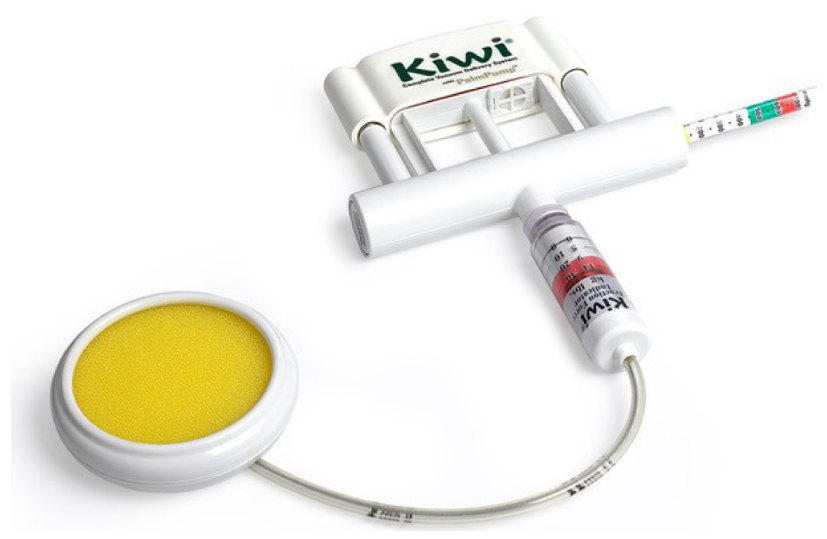

Figure I Kiwi ${ }^{\circledR}$ OmniCup ${ }^{\circledR}$ Complete Vacuum Delivery System with PalmPump ${ }^{\mathrm{TM}}$. vacuum group (681 vs $810 \mathrm{cc}$ ), but there were no differences in neonatal outcomes such as Apgar scores or birth weight ( $3.5 \mathrm{~kg}$ vs $3.6 \mathrm{~kg}, P=0.6$ ), between groups. In the manual extraction group, four patients $(16 \%)$ required uterine extensions and one had evidence of a cervical laceration. No uterine extensions or cervical lacerations occurred in the vacuum group. There were three reported cases of cosmetic scalp effects, such as bruising or presence of a chignon, in neonates delivered with vacuum, although all were judged minor and resolved spontaneously within 1 week. In these three instances, the cup was not positioned correctly over the flexion point and pop-offs occurred. In cases where the cup was appropriately placed over the flexion point and the integrity of the vacuum was maintained without pop-offs, there was no evidence of scalp effects.

\section{Discussion}

While some early adopters promoted the commonly held misconception that little skill is required to use the vacuum device, ${ }^{10}$ we offer a more cautious perspective given the preponderance of clinical experience. 1) Based on the formative work by Solomons ${ }^{11}$ and Bercovici, ${ }^{12}$ those infants who are unengaged or "floating" more readily lend themselves to the use of the vacuum during cesarean section. 2) Awareness of the fetal head position is of the upmost importance in allowing the surgeon the best opportunity to position the cup properly to ensure vacuum integrity without inadvertent cup detachments. In accordance with the instructions provided by Bofill et al, ${ }^{17}$ the cup should be placed over the flexion point, $\sim 3 \mathrm{~cm}$ anterior to the posterior fontanelle along the sagittal suture. This is the point at which the mentovertical diameter crosses the sagittal suture, promoting flexion of the fetal neck and thus presenting the smallest diameter of the fetal head to the uterine incision. ${ }^{7}$ 3) Posterior-designed cups allow easier maneuverability of the vacuum device over the flexion point within the confines of the uterine incision. 4) The traction force should be minimized and the extent of the incision should not limit safe passage of the fetal head and body. Additional contraindications of vacuum delivery include prematurity ( $<36$ weeks gestation), a known fetal blood or bone demineralization disorder, or known maternal viral infection. 5) Although less likely to occur during cesarean section, use of the vacuum should be discontinued after two pop-offs have occurred or after 20 minutes have elapsed.

There have been few neonatal adverse events reported in the literature related to the use of vacuum-assisted cesarean section. However, complications such as scalp abrasions, 
retinal hemorrhages, jaundice, and cephalohematomas have been reported with vacuum-assisted operative vaginal delivery. ${ }^{7}$ More serious complications can include intracranial hemorrhages and skull fractures; however, these rare events are likely associated with misplacement of the cup, excessive traction force, and multiple pop-offs during operative vaginal deliveries. ${ }^{20,21}$ As speculated by Solomons, ${ }^{11}$ the force required to deliver the fetal head through the abdominal incision is less than the force required to deliver the head across the perineal floor during a vaginal delivery; thus, excessive tractions and pop-offs should be rare with cesarean section. To reemphasize, if there is difficulty delivering the fetal head through the abdominal incision, immediate attention should be paid to the sizes of the skin, fascial, and uterine incisions. The size of the incision should not be limited at the expense of safely delivering the fetus.

The combination of increasing cesarean section use and the decreasing willingness to allow vaginal birth after cesarean section will likely result in an expansion of the use of vacuum assistance. When the vacuum device is used appropriately, the delivery can be facilitated by effectively decreasing the volume delivered through the uterine incision due to the avoidance of a delivering hand or forceps blade. The vacuum may lead to decreased uterine extensions and decrease in blood loss associated with efforts to deliver the head in difficult cases. Without the need for excessive fundal pressure, maternal discomfort can be minimized. Based on the published literature and pragmatic clinical experience, the use of the vacuum device is a safe and effective technique to assist delivery during cesarean section.

\section{Acknowledgment}

Development of this manuscript was supported by Clinical Innovations (Salt Lake City, UT, USA).

\section{Disclosure}

Dr McQuivey is an employee of and Dr Block is an independent advisor to Clinical Innovations (Salt Lake City, UT, USA). The authors report no other conflicts of interest in this work.

\section{References}

1. Molina G, Weiser TG, Lipsitz SR, et al. Relationship between cesarean delivery rate and maternal and neonatal mortality. JAMA. 2015; 314(21):2263-2270.
2. Hamilton BE, Martin JA, Ventura SJ. Births: preliminary data for 2011. Natl Vital Stat Rep. 2012;61(5):1-18.

3. MacDorman MF, Menacker F, Declercq E. Cesarean birth in the United States: epidemiology, trends, and outcomes. Clin Perinatol. 2008;35(2): 293-307, v.

4. Kozhimannil KB, Law MR, Virnig BA. Cesarean delivery rates vary tenfold among US hospitals; reducing variation may address quality and cost issues. Health Aff (Millwood). 2013;32(3):527-535.

5. Spong CY, Berghella V, Wenstrom KD, Mercer BM, Saade GR. Preventing the first cesarean delivery: summary of a joint Eunice Kennedy Shriver National Institute of Child Health and Human Development, Society for Maternal-Fetal Medicine, and American College of Obstetricians and Gynecologists Workshop. Obstet Gynecol. 2012;120(5):1181-1193.

6. Declercq E, Young R, Cabral H, Ecker J. Is a rising cesarean delivery rate inevitable? Trends in industrialized countries, 1987 to 2007. Birth. 2011;38(2):99-104.

7. McQuivey RW. Vacuum-assisted delivery: a review. J Matern Fetal Neonatal Med. 2004;16(3):171-180.

8. Ali UA, Norwitz ER. Vacuum-assisted vaginal delivery. Rev Obstet Gynecol. 2009;2(1):5-17.

9. Waterfall H, Grivell RM, Dodd JM. Techniques for assisting difficult delivery at caesarean section. Cochrane Database Syst Rev. 2016;1: CD004944.

10. Nakano R. Use of the vacuum extractor for delivery of the fetal head at cesarean section. Am J Obstet Gynecol. 1981;141(4):475-476.

11. Solomons E. Delivery of the head with the Malmstrom vacuum extractor during cesarean section. Obstet Gynecol. 1962;19:201-203.

12. Bercovici B. Use of vacuum extractor for head delivery at Cesarean section. Isr J Med Sci. 1980;16(3):201-203.

13. Pelosi MA, Apuzzio J. Use of the soft, silicone obstetric vacuum cup for delivery of the fetal head at cesarean section. J Reprod Med. 1984; 29(4):289-292.

14. Johanson R, Menon V. Soft versus rigid vacuum extractor cups for assisted vaginal delivery. Cochrane Database Syst Rev. 2000;2: CD000446.

15. Arad I, Linder N, Bercovici B. Vacuum extraction at cesarean sectionneonatal outcome. J Perinat Med. 1986;14(2):137-140.

16. Boehm FH. Vacuum extraction during cesarean section. South Med J. 1985;78(12):1502.

17. Bofill JA, Lencki SG, Barhan S, Ezenagu LC. Instrumental delivery of the fetal head at the time of elective repeat cesarean: a randomized pilot study. Am J Perinatol. 2000;17(5):265-269.

18. Dimitrov A, Pavlova E, Krusteva K, Nikolov A. [Caesarean section with vacuum extraction of the head]. Akush Ginekol (Sofia). 2008; 47(3):3-6.

19. Sritippayawan S, Chantrapitak W. Assisted delivery of high floating fetal head: a comparison of vacuum-assisted delivery and manual extraction. Asian Biomed. 2011;5(5):699-703.

20. Clark SL, Vines VL, Belfort MA. Fetal injury associated with routine vacuum use during cesarean delivery. Am J Obstet Gynecol. 2008; 198(4):e4.

21. Fareeduddin R, Schifrin BS. Subgaleal hemorrhage after the use of a vacuum extractor during elective cesarean delivery: a case report. J Reprod Med. 2008;53(10):809-810. 
International Journal of Women's Health

Dovepress

\section{Publish your work in this journal}

The International Journal of Women's Health is an international, peerreviewed open-access journal publishing original research, reports, editorials, reviews and commentaries on all aspects of women's healthcare including gynecology, obstetrics, and breast cancer. The manuscript management system is completely online and includes

Submit your manuscript here: http://www.dovepress.com/international-journal-of-womens-health-journa a very quick and fair peer-review system, which is all easy to use. Visit http://www.dovepress.com/testimonials.php to read real quotes from published authors. 